\title{
ARTIGOS
}

\section{UM PANORAMA DA LÓGICA DEÔNTICA ${ }^{1}$}

\author{
Nelson Gonçalves Gomes* \\ gomes@unb.br
}

RESUMO O presente artigo é uma apresentação dos principais sistemas de lógica deôntica, na qual algumas conexões éticas e jurídicas relevantes são enfatizadas.

Palavras-chave Sistemas de lógica deôntica; Paradoxos deônticos; Obrigação e ação.

ABSTRACT This article contains a general survey of the main systems of deontic logic, emphasizing some ethical and legal relevant connections.

Keywords Systems of deontic logic; Deontic paradoxes; Obligation and action.

\section{Noções introdutórias}

Lógica é a disciplina que investiga os princípios da argumentação válida. Em particular, a lógica deôntica estuda a validade de argumentos nos quais frases regidas por expressões como É obrigatório que..., É permitido $q u e . .$. desempenham papel relevante. A primeira dessas expressões pode ser representada pela letra maiúscula $\mathrm{O}$ (operador de obrigação), sendo que a

1 Uma versão resumida deste artigo foi publicada como verbete no Dicionário de filosofia moral e política, organizado pelo Prof. António Marques, da Universidade Nova de Lisboa. O verbete tem o título "Lógica Deôntica".

* Professor do Departamento de Filosofia da Universidade de Brasília (UnB). Artigo recebido em setembro de 2007 e aprovado em março de 2008.

KRITERION, Belo Horizonte, nº 117, Jun./2008, p. 9-38. 
segunda é simbolizada por P (operador de permissão). Por exemplo, se $p$ for a frase Impostos são pagos, $\mathrm{O} p$ e $\mathrm{P} p$ devem ser lidas, respectivamente, das seguintes maneiras: É obrigatório que impostos sejam pagos, É permitido que impostos sejam pagos. A lógica deôntica recebe o seu nome da palavra grega déon (necessidade, o que é preciso). Em resumo, essa lógica pode ser entendida como a lógica das normas, no sentido do que seja obrigatório ou permitido.

Existe um conjunto de sistemas chamados de lógicas intensionais (com "s"), cujas linguagens, em geral, envolvem semânticas que fazem uso da noção de mundo possível. O mundo real é um mundo possível. Variações do repertório presente na realidade também são mundos possíveis, de modo que uma situação na qual Hamburgo seja a capital da Alemanha, por exemplo, embora não seja real, é parte de um mundo possível. Igualmente possível é um mundo no qual ainda existam dinossauros. A lógica deôntica pode ser vista como um sistema intensional que exige formas específicas de semânticas dos mundos possíveis.

O mais importante dentre os sistemas intensionais é a lógica modal, que se interessa por argumentos nos quais frases regidas por expressões como $E$ necessário que..., É possível que... tenham função crucial. Seja L o operador modal que representa $E$ necessário que... e seja a expressão $E^{\prime}$ possível que... simbolizada por M. Se $q$ significa que $2+2=4$, então L $q$ e M $q$ devem ser lidas como É necessário que $2+2=4$ e É possível que $2+2=4$, respectivamente. Se a frase $\mathrm{L} q$ for verdadeira, então $q$ deve ser verdadeira em todos os mundos possíveis. Portanto, como a fórmula $2+2=4$ jamais é falsa, $\mathrm{L}(2+2=4)$ é uma frase verdadeira. Por sua vez, Mq será uma frase verdadeira se $q$ for verdadeira em ao menos um mundo possível. Nesses termos, visto que a frase A malária está erradicada talvez venha a ser verdade, algum dia, a asserção M(A malária está erradicada) é uma frase verdadeira.

A lógica modal é uma extensão da lógica elementar, de modo que nela são empregados os conhecidos operadores lógicos: (não), \& (e), $\vee($ ou $), \supset$ (se..., então...), $\equiv$ (...se, e somente se,...), $\forall$ (para todo), $\exists$ (existe ao menos um). Nesse contexto, o assim chamado operador de necessidade (L) pode ser tomado como primitivo, definindo-se a partir dele o operador de possibilidade (M). Se $p$ for uma frase, $\mathrm{M} p$, por definição, será o mesmo que $\sim \mathrm{L} \sim p$. Por exemplo, a frase É possível que chova diz o mesmo que Não é necessário que não chova. Por outro lado, o operador $\mathrm{M}$ pode ser aceito como primitivo, definindo-se, então, o operador L: L $p$, por definição, diz o mesmo que $\sim \mathrm{M} \sim p$. Por exemplo, a frase É necessário que $2+2=4$ equivale à asserção Não é possivel que $2+2 \neq 4$. 
Os operadores modais L e M são chamados aléticos, enquanto que $\mathrm{O}$ e P são os operadores deônticos. A semelhança entre eles é notável, na medida em que as relações entre $\mathrm{L}$ e $\mathrm{M}$ são paralelas às conexões existentes entre $\mathrm{O}$ e P. Com efeito, se $\mathrm{O}$ for tomado como primitivo, $\mathrm{P}$ é introduzido da seguinte maneira: $\mathrm{P} p$, por definição, é o mesmo que $\sim \mathrm{O} \sim p$. Se $\mathrm{P}$ for primitivo, $\mathrm{O}$ é definido correspondentemente: $\mathrm{O} p$, por definição, é o mesmo que $\sim \mathrm{P} \sim p$. Portanto, afirmar que é permitido o consumo de bebidas alcoólicas, num certo ambiente, equivale a dizer que ali não é obrigatório que não se tomem tais bebidas. Por outro lado, afirmar que o pagamento de impostos é obrigatório é o mesmo que dizer que não é permitido não pagar impostos.

Aparentemente, a semelhança entre operadores L e M, de um lado, e O e $\mathrm{P}$, de outro, sugere que a lógica deôntica seja uma variação irrelevante da lógica modal. Não obstante, essa conclusão seria enganosa. Num sistema modal elementar chamado $\mathbf{T}$, a fórmula $\mathrm{L} p \supset p$ é válida. Ora, tal fórmula diz tão-somente que, se a frase $p$ for necessária, então $p$ será verdadeira (se é necessário que $2+2=4$, então é verdade que $2+2=4$ ). Nesse mesmo sistema $\mathbf{T}$, demonstra-se que, se $p$ for verdadeira, então $p$ é possível, ou seja, $p \supset \mathrm{M} p$ (se é verdade que esteja chovendo, então é possível que esteja chovendo). $\mathrm{Na}$ lógica deôntica, existem princípios correspondentes a essas frases modais? A resposta a essa pergunta é negativa, pois a lógica deôntica deve capturar as idéias básicas relativas a obrigações e permissões. Sabidamente, nem sempre as obrigações são cumpridas, de modo que os sistemas normativos, de alguma forma, têm de admitir um Princípio de Precariedade (De Greef, 2003). Logo, na lógica deôntica, não pode valer a frase $\mathrm{O} p \supset p$, pois esta afirma que o que é obrigatório é verdadeiro, ou seja, que a norma é sempre cumprida. Nesse tipo de lógica, tampouco pode valer a frase $p \supset \mathrm{P} p$, porquanto, segundo esta, o que é verdadeiro é permitido. Ora, se $p$ é a frase Caim matou Abel, então $p$ é verdadeira, mas daí não se infere que matar Abel tenha sido permitido a Caim.

As primeiras reflexões sobre lógica deôntica remontam ao século XIV (Knuuttila, 1981). Em 1926, já sob o impacto da lógica matemática, o austríaco Ernst Mally escreveu um minucioso livro pioneiro sobre a lógica do dever (Mally, 1926). Entre 1937 e 1939, Jørgen Jørgensen, Karl Menger, Albert Hofstadter e J. C. C. McKinsey também escreveram textos nessa área. Porém, por várias razões, todos esses estudos das décadas de 20 e 30 tinham insuficiências importantes (Føllesdal; Hilpinen, 1971). Em 1951, o finlandês Georg Henrik von Wright publicou o artigo "Deontic Logic", também pioneiro e ainda insatisfatório, mas que veio a desempenhar um papel seminal, pelo avanço que representou relativamente aos seus antecessores (von Wright, 
1951). Esse artigo de von Wright foi debatido e aperfeiçoado por vários lógicos, daí resultando o assim chamado sistema-padrão, que pode ser considerado como maduro e logicamente plausível (Føllesdal; Hilpinen, 1971).

\section{O sistema-padrão}

Seja o operador de obrigação $(\mathrm{O})$ tomado como primitivo. Com o seu auxílio, os três axiomas do sistema-padrão podem ser formulados, da seguinte maneira:
A1. $\mathrm{O} p \supset \sim \mathrm{O} \sim p$
A2. $\mathrm{O}(p \& q) \equiv(\mathrm{O} p \& \mathrm{O} q)$
A3. $\mathrm{O}(p \vee \sim p)$

Como $\mathrm{P}$, por definição, equivale a $\sim \mathrm{O} \sim$, o axioma $\mathrm{A} 1$ diz o mesmo que a fórmula $\mathrm{O} p \supset \mathrm{P} p$. Ora, esta última é o Princípio de Permissão ou Princípio da Consistência Deôntica, segundo o qual tudo o que é obrigatório é também permitido (se é obrigatório pagar impostos, então é permitido pagá-los). Consoante o axioma A2, se a conjunção das frases $p$ e $q$ expressa obrigações, então tanto $p$ quanto $q$, tomadas singularmente, também expressam obrigações (se é obrigatório declarar lucros e pagar impostos, então é obrigatório declarar lucros e é obrigatório pagar impostos). Por sua vez, o axioma A3 estabelece a obrigatoriedade do Princípio de Terceiro Excluído (é obrigatório que impostos sejam pagos ou que não sejam pagos).

As regras de inferência do sistema-padrão são as seguintes:

Regra da substituição de variáveis proposicionais: O resultado da substituição uniforme de uma variável proposicional por uma fórmula, num teorema, também é um teorema.

Regra do modus ponens: Se $p$ e $p \supset q$ forem teoremas, então $q$ também o será.

Regra da extensionalidade deôntica: Se $p$ e $q$ forem frases equivalentes, então $\mathrm{P} p$ e $\mathrm{P} q$ também o serão.

Se a letra F representa a expressão É proibido que..., então a frase Fp (é proibido que $p$ ) pode ser introduzida, por definição, como sendo equivalente a $\sim \mathrm{P} p$ ou a $\mathrm{O} \sim p$. Nesses termos, se for proibido que Caim mate Abel, então não é permitido que Caim mate Abel, assim como é obrigatório que Caim não mate Abel. 
A partir dos axiomas e regras do sistema-padrão, os seguintes teoremas podem ser derivados, dentre outros:

$\bullet \sim(\mathrm{O} p \& \mathrm{O} \sim p)$

Segundo essa frase, não é o caso que tanto $p$ quanto $\sim p$ sejam obrigatórios, vale dizer, não há obrigações mutuamente contraditórias.

- $[(\mathrm{O} p \supset \mathrm{O} q) \& \mathrm{O} p] \supset \mathrm{O} q$

Se a eventual obrigatoriedade de uma frase implica a obrigatoriedade de uma outra e se a primeira é obrigatória, então a segunda também o é. (Se a frase É obrigatório que lucros sejam declarados implica É obrigatório que impostos sejam pagos e se, realmente, aquela primeira for verdadeira, então esta última também o será.) Este é o modus ponens deôntico.

- $[(\mathrm{O} p \supset \mathrm{O} q) \& \mathrm{P} p] \supset \mathrm{P} q$

Se a eventual obrigatoriedade de uma frase implica a obrigatoriedade de uma outra e se a primeira for permissível, então a segunda também o será. (Se a frase É obrigatório que lucros sejam declarados implicar É obrigatório que impostos sejam pagos, e se a frase Lucros são declarados expressar algo permissível, então Impostos são pagos também expressará algo permissível.)

- [O $(p \vee q) \&(\mathrm{~F} p \& \mathrm{~F} q)]$

Conforme esse teorema, não pode ocorrer que uma disjunção seja obrigatória e os seus membros sejam ambos proibidos. Tomás de Aquino concorda com essa tese e diz que um homem está perplexus simpliciter se, aparentemente, ele estiver obrigado a fazer coisas proibidas. Numa situação assim, ou não há verdadeira obrigação, ou não há ao menos uma dentre as proibições.

- $\{\mathrm{O}[p \supset(q \vee r)] \&(\mathrm{~F} q \& \mathrm{~F} r)\} \supset \mathrm{F} p$

Esse teorema pode ser entendido da seguinte maneira: se for obrigatória uma implicação, cujo conseqüente seja constituído por frases proibidas, então, o respectivo antecedente também será proibido. Em outras palavras: se alguém chegar a uma situação na qual tenha de fazer algo errado, então ele terá cometido um erro, ao início de tudo. Sob tais circunstâncias, segundo 
Tomás de Aquino, o agente está perplexus secundum quid. O motorista que entrar numa rua proibida pode ser obrigado a retornar em marcha à ré, o que não é permitido. Porém, antes de cometer esse segundo erro, ele cometeu um primeiro, ao entrar numa rua que lhe estava fechada (von Wright, 1951, p. 14; Tomás de Aquino, 1980, Suma Teológica, IaIIae, q. 19. art. 6).

- $\mathrm{O} p \supset \mathrm{O}(p \vee q)$

A propósito deste teorema, Alf Ross obtemperou o seguinte: se $p$ representar o estado de coisas no qual se põe uma carta no correio e $q$ a situação de se queimar essa carta, então, caso seja obrigatório pôr uma carta no correio, será também obrigatório que se a ponha no correio ou que se a queime? Em outras palavras, quem receber a ordem de pôr uma carta no correio poderá escolher entre remetê-la ou queimá-la (Ross, 1941)? Esse é o assim chamado paradoxo de Ross que, entretanto, não faz jus a tal denominação. Na verdade, a obrigação de realizar $p$ ou $q$ vem antecedida pela obrigação de realizar $p$, de modo que não existe a possibilidade de escolha entre pôr a carta no correio ou queimá-la (Ziemba, 1981, p. 99).

$$
\text { - } \mathrm{F} p \supset \mathrm{O}(p \supset q)
$$

Esse é o teorema da obrigação derivada (derived obligation), segundo o qual se um agente faz algo proibido $p$, então, obrigatoriamente, o que ele fez gera uma obrigação $q$. (Se alguém causa um acidente, está sujeito às conseqüências.)

$$
\text { - } \sim p \supset(p \supset \mathrm{O} q)
$$

Esse é o teorema do compromisso (commitment). Essa frase não é intuitiva, pois afirma que se $p$ não for verdadeira, então $p$ implica qualquer obrigação $q$. (Se é falso que João tenha causado um acidente, então, se João causou esse acidente, ele está sujeito a qualquer obrigação q.)

$$
\text { - } \mathrm{F} p \supset \mathrm{F}(p \& q)
$$

Esse é o teorema do bom samaritano. Se o estado de coisas descrito na frase $p$ é proibido, então é também proibido o estado de coisas descrito em $p$ $\& q$. (Se for proibido roubar o dinheiro de alguém, então é proibido roubá-lo e gastá-lo.) 
Há quem entenda que o teorema do bom samaritano seja paradoxal. Considere-se, a propósito, a seguinte situação: um viajante é atacado e roubado por um ladrão, que o deixa sangrando, à beira do caminho. Em alguns instantes, porém, o ladrão lembra-se do samaritano citado no Evangelho, arrepende-se, retorna e socorre a sua vítima. Mas, segundo o teorema ora em pauta, se é proibido ao ladrão atacar a vítima $(p)$, é-lhe também proibido atacá-la $(p)$ e socorrê-la $(q)$. Nesses termos, o teorema do bom samaritano daria origem a um paradoxo do bom samaritano, pois a boa ação descrita na frase $q$ seria proibida, quando viesse a ocorrer num contexto mais amplo de proibição.

$\mathrm{Na}$ verdade, esta versão do paradoxo do bom samaritano é apenas aparente. Por definição, o teorema $\mathrm{F} p \supset \mathrm{F}(p \& q)$ equivale a $\mathrm{O} \sim p \supset \mathrm{O} \sim(p$ $\& q)$. Consoante uma das leis de De Morgan, esta última frase equivale a $\mathrm{O} \sim p \supset \mathrm{O}(\sim p \vee \sim q)$. Ora, com isso o paradoxo desaparece, pois o teorema em pauta diz apenas que, se é obrigatório evitar-se a situação descrita em $p$, então, obrigatoriamente, o que está descrito em $p$ e/ou em $q$ deve ser evitado. (Forrester (1996, p. 144) apresenta uma versão mais forte do paradoxo do bom samaritano.)

\section{A semântica dos mundos deonticamente perfeitos}

A linguagem do sistema-padrão carece de um tipo especial de semântica dos mundos possíveis, conhecida como semântica dos mundos deonticamente perfeitos, que se desenvolveu, sobretudo, a partir de trabalhos de Stig Kanger 1971[1957], Saul Kripke (1963a, 1963b) e Jaakko Hintikka (1957, 1970).

A tarefa fundamental da semântica dos mundos possíveis é estabelecer as condições sob as quais frases dos tipos $\mathrm{O} p$ e $\mathrm{P} p$ são verdadeiras ou falsas, assim como definir as noções de consistência e de conseqüência, no contexto de uma linguagem deôntica. Isso é feito em etapas. Em primeiro lugar, caracteriza-se uma condição mínima $\mathrm{C}$, que define o que seja um conjunto consistente de frases deônticas. Seja A um conjunto que contenha $n$ obrigações e uma permissão: $\mathrm{A}=\left\{\mathrm{O} p_{1}, \mathrm{O} p_{2}, \ldots, \mathrm{O} p_{n}, \mathrm{P} q\right\}$. A condição $\mathrm{C}$ estabelece que se $\left\{\mathrm{O} p_{1}, \mathrm{O} p_{2}, \ldots, \mathrm{O} p_{n}, \mathrm{P} q\right\}$ for consistente, então $\left\{p_{1}, p_{2}, \ldots, p_{n}, q\right\}$ também deve ser consistente. Em outras palavras, um conjunto de frases que contenha $n$ obrigações e uma permissão será consistente se, e somente se, a realização do que é permitido (isto é, $q$ ) for compatível com a realização daquilo que é obrigatório (isto é, $p_{1}, p_{2}, \ldots, p_{n}$ ). Se for permitido fumar, então isso poderá ser feito sem que o respectivo agente venha a ferir qualquer lei.

Em seguida, é introduzido o conceito de mundos deonticamente alternativos, com respeito ao mundo real. Suponhamos que $m_{0}$ seja o mundo 
real, no qual estão consistentemente estabelecidas as obrigações $\mathrm{O} p_{1}, \mathrm{O} p_{2}, \ldots$, $\mathrm{O} p_{n}$ e a permissão $\mathrm{P} q$. O mundo possível $m_{1}$ será uma alternativa deôntica a $m_{0}$ se, e somente se, em $m_{1}$, as obrigações descritas nas frases $p_{1}, p_{2}, \ldots, p_{n}$ e a permissão expressa pela frase $q$ são realizadas, também consistentemente. Em outras palavras, no mundo $m_{1}$, as obrigações vigentes em $m_{0}$ são cumpridas e ao menos uma permissão de $m_{0}$ é realizada. Nesse caso, $m_{1}$ será um mundo deonticamente perfeito, com respeito a $m_{0}$.

Com o auxílio desses conceitos, nós podemos estabelecer as condições de verdade de frases como $\mathrm{O} p$ e $\mathrm{P} p$. O $p$ é uma frase verdadeira, em $m_{0}$, se, e somente se, $p$ for verdadeira em todos os mundos deonticamente perfeitos, relativamente a $m_{0}$. P $p$ é uma frase verdadeira, em $m_{0}$, se, e somente se, $p$ for verdadeira em ao menos um mundo deonticamente perfeito, relativamente a $m_{0}$.

Quando um legislador apresenta um projeto de lei, ele lança mão dos conceitos ora definidos, na medida em que tenta provar que haveria progresso se as obrigações ali propostas fossem, de fato, realizadas. Se ele propõe uma permissão, deve mostrar que esta nada envolve de ilegal. Esses modos de falar recorrem a idealizações que são mundos deonticamente perfeitos.

Quantos mundos deonticamente perfeitos existem? Com certeza, não será apenas um. Se $p$ significar Alguém fuma, então $\mathrm{P} p$ afirmará que é permitido fumar e $\mathrm{P} \sim p$ que é permitido não fumar. Ora, como essas frases são ambas verdadeiras, no mundo real, devem existir pelo menos dois mundos deonticamente perfeitos, sendo que no primeiro se fuma e no segundo não.

O Princípio de Precariedade atesta que, no mundo real $m_{0}$, há normas nãocumpridas. Logo, $m_{0}$ não é um mundo deonticamente perfeito, com respeito a si mesmo. Isso torna claro por que frases como $\mathrm{O} p \supset p$ e $p \supset \mathrm{P} p$ podem ser falsas, no contexto da presente semântica. Com efeito, em $m_{0}$, a frase $\mathrm{O} p$ pode ser verdadeira, embora $p$ seja falsa, ou seja, nesse mundo, uma obrigação pode existir, mesmo sem ser observada. Por outro lado, em $m_{0}, p$ pode ser verdadeira e $\mathrm{P} p$ falsa, de modo que $p \supset \mathrm{P} p$ será falsa.

Na semântica dos mundos deonticamente perfeitos, conceitos usuais como verdade lógica, conseqüência, etc. são definidos sem maiores dificuldades. No contexto dessa semântica, prova-se que o sistema-padrão é correto (sound), consistente e completo. Sendo ele correto, todos os seus teoremas são frases verdadeiras, sob quaisquer circunstâncias. Sendo ele consistente, o conjunto dos seus teoremas é isento de contradições. Sendo ele completo, todas as frases que forem verdadeiras sob quaisquer circunstâncias são também teoremas. 
Sob um ponto de vista histórico, mundos deonticamente perfeitos são aparentados com o império das finalidades, um conceito introduzido por Kant, em 1785:

Pois entes racionais estão sujeitos à lei segundo a qual cada um deve tratar a si mesmo e a todos os outros jamais como simples meio, mas sempre também como finalidade em si mesma. A partir daí, porém, emerge uma relação sistemática entre entes racionais, através de leis comunitárias objetivas, isto é, um império que pode ser chamado de império das finalidades (obviamente, ideal), pois essas leis têm como intenção as relações entre tais entes, como finalidades e meios.

É próprio de um ente racional, como membro do império das finalidades, se ele é ali legislador geral, que esteja também submetido à mesma lei. (Kant, 1968[1785], parte II, p. 433)

Esta idéia de um império das finalidades foi o instrumento teórico através do qual Kant conseguiu caracterizar as relações morais entre seres dotados de razão, partindo do princípio de que tais seres jamais serão tratados tãosomente como meios, mas sempre como fins. É interessante observar que Kant enfatizou a impossibilidade de qualquer imperfeição, no quadro de relações assim caracterizadas, pois ali nunca se agirá contra a finalidade moral autônoma (ibidem, p. 437).

Em resumo, a semântica dos mundos perfeitos toma o conjunto dos mundos possíveis e subdivide-o em duas classes, sendo que um mundo $m_{0}$ é o ponto de referência de tal subdivisão. De um lado, ficam os mundos perfeitos relativamente a $m_{0}$; de outro, ficam os mundos não-perfeitos, entre os quais está $m_{0}$. Essa subdivisão é plausível, na medida em que os mundos possíveis podem incluir ações humanas, aceitáveis ou não. Os mundos que abrigarem apenas ações aceitáveis relativamente às normas vigentes em $m_{0}$ serão perfeitos, sendo não-perfeitos todos os restantes. As obrigações ideais (ou prima facie) de um indivíduo podem ser satisfatoriamente caracterizadas, com o auxílio da idéia de mundos deonticamente perfeitos (Hilpinen, 2001, p. 163 e 172).

Vale a pena enfatizar que, se a frase modal-alética L $p$ for verdadeira, então $p$ será verdadeira em todos os mundos possíveis, sem exceção. Por outro lado, se a frase deôntica $\mathrm{O} p$ for verdadeira, $p$ será verdadeira tão-somente em todos os mundos deonticamente perfeitos. É fácil confundir as condições de verdade desses dois tipos de frases, mesmo porque a própria expressão déon significa o que é necessário e o que é preciso. 


\section{Paradoxos deônticos}

A tese segundo a qual existiria um conjunto $x$, tal que $x \in x \& x \notin x$ é o célebre paradoxo de Russell, que evidenciou a inadequação do sistema construído por Frege para fundamentar a aritmética. Esse paradoxo é uma contradição, cuja demonstrabilidade no referido sistema mostra que há ali algo de errado, no que diz respeito à noção de pertença $(\in)$.

Visto que o sistema-padrão é correto e consistente, nele nenhuma contradição é teorema. Portanto, no sistema-padrão, não há paradoxos como o de Russell. Entretanto, nesse sistema surgem dificuldades importantes que, numa acepção bem mais fraca, são chamadas de paradoxos deônticos.

No seu ensaio de 1951, p. 4, von Wright define o conceito de compromisso da seguinte maneira: $\mathrm{O}(p \supset q)$. Nesses termos, se $p$ significar João assinou o contrato e $q$ for a frase Ele cumpre as respectivas cláusulas, então, segundo von Wright, $\mathrm{O}(p \supset q)$ declara que, em assinando o contrato, João está comprometido com o cumprimento das respectivas cláusulas.

$\mathrm{O}$ assim chamado paradoxo da obrigação derivada (paradox of derived obligation) diz respeito a essa definição. Se a expressão $\mathrm{O}(p \supset q)$ define compromisso, o teorema da obrigação derivada, $\mathrm{F} p \supset \mathrm{O}(p \supset q)$, afirma que quem executa uma ação proibida, descrita na frase $p$, está obrigado a qualquer coisa descrita em $q$. Ora, isso é inaceitável, em termos deonticamente intuitivos, pois quem pára o seu carro num lugar proibido nem por isso está sujeito a qualquer tipo de punição.

Em 1962, Prior apresenta uma outra definição de compromisso, nos seguintes termos: $p \supset \mathrm{O} q$ (Prior, 1962, p. 224-225, apud Føllesdal; Hilpinen, 1971 , p. 24). Nos termos do exemplo anterior, ao assinar o contrato, João compromete-se com o cumprimento das respectivas cláusulas.

O teorema do compromisso, $\sim p \supset(p \supset \mathrm{O} q)$, mostra que a definição de Prior também é problemática. Se $p \supset \mathrm{O} q$ for a definição de compromisso, o teorema diz que aquilo que não acontece $(\sim p)$ obriga-nos a qualquer coisa $(q)$. Esse resultado inaceitável é o paradoxo do compromisso (paradox of commitment).

Em 1963, R. M. Chisholm formulou um novo paradoxo, que envolve aquilo que se chama de obrigações reparadoras (contrary-to-duty imperatives), obrigações essas que são caracterizadas quando o agente deixa de cumprir o seu dever, cabendo-lhe, então, reparar o que foi feito (Chisholm, 1963). Considere-se, por exemplo, o seguinte conjunto de frases: 
1. É obrigatório que João ajude seus parentes pobres.

2. Obrigatoriamente, se João ajudar seus parentes pobres, ele dirá que os ajuda.

3. Se João não ajudar seus parentes pobres, então, obrigatoriamente, ele não dirá que os ajuda.

4. João não ajuda os seus parentes pobres.

Esta última frase é contingente e indica que João falha no cumprimento do seu dever. Mas, ao que tudo indica, esse conjunto de quatro frases da linguagem natural é consistente, embora nenhuma delas seja verdadeira sob quaisquer circunstâncias. As normas 1, 2 e 3 são plausíveis, e a frase 4 nada contém que leve a contradições. Não obstante, ao formular essas frases na linguagem do sistema-padrão, obtém-se um conjunto de fórmulas que é inconsistente. Seja $p$ a frase João ajuda os seus parentes pobres e $q$ a frase João diz que ajuda os seus parentes pobres. As frases 1, 2, 3 e 4 têm, respectivamente, a seguinte formalização:
5. $\mathrm{O} p$
6. $\mathrm{O}(p \supset q)$
7. $\sim p \supset \mathrm{O} \sim q$
8. $\sim p$

À primeira vista, parece que 5, 6, 7 e 8 traduzem 1, 2, 3 e 4. Porém, a prova de que isso não é o caso, está na contradição que se deriva de tais fórmulas, de sorte que elas formam um conjunto inconsistente. A derivação de contradições é aqui a seguinte:

9. $\mathrm{O} \sim q$

7,8 Modus ponens

10. $\mathrm{O}(p \supset q) \supset(\mathrm{O} p \supset \mathrm{O} q)$ Teorema do sistema-padrão

11. $\mathrm{O} p \supset \mathrm{O} q$

6,10 Modus ponens

12. $\mathrm{O} q$

5,11 Modus ponens

13. $\mathrm{O} q \supset \sim \mathrm{O} \sim q$

Axioma A1, subst. $p$ por $q$

14. $\sim \mathrm{O} \sim q$

12,13 Modus ponens

As fórmulas 9 e 14 são mutuamente contraditórias. Além disso, outras possibilidades de formalização das frases 1, 2, 3 e 4 também conduzem a resultados insatisfatórios (Føllesdal; Hilpinen, 1971, p. 23-25). 
Como observa Hansson (1971[1970], p. 132-133), as obrigações expressas nas frases 1 e 2 são diferentes da obrigação veiculada por meio de 3. Esta última é a obrigação reparadora que se caracteriza quando 1 é violada. Como o sistema-padrão é consistente, o fracasso das formalizações apenas mostra que 3 não pode ser expressa, no sistema-padrão. Em outras palavras, nesse sistema não há como expressar a obrigação reparadora, o que é uma significativa insuficiência.

Na verdade, as obrigações prima facie expressas nas frases 1 e 2 cumpremse em todos os mundos deonticamente perfeitos. A obrigação expressa em 3, porém, diz respeito ao que o agente deva fazer, depois de não ter cumprido o seu dever, isto é, se $\sim p$ for verdadeira. Ora, o mundo no qual isto venha a ser o caso não será deonticamente perfeito. Logo, o sistema-padrão e a semântica dos mundos perfeitos expressam obrigações prima facie, mas falham em capturar a obrigação reparadora.

É interessante observar que as frases 6 e 7 expressam compromissos, respectivamente, segundo as definições de von Wright e de Prior. Nesse sentido, o paradoxo da obrigação reparadora articula os paradoxos da obrigação derivada e do compromisso.

Como os teoremas da obrigação derivada e do compromisso são demonstrados com o auxílio da frase $\sim p \supset(p \supset q)$, que é teorema da lógica proposicional comum, alguns autores sugerem o emprego de um cálculo básico que não contenha tal frase (Weingartner, 2001, p. 60 et seq.). Entretanto, essa não é a estratégia privilegiada por von Wright. Reconhecendo que o sistemapadrão é insuficiente, por não dispor de recursos para expressar o conceito de obrigação reparadora, ele lança mão da idéia de obrigação condicional. Isso o leva a formular uma lógica deôntica diádica.

\section{A lógica deôntica diádica}

Numa lógica diádica, os operadores deônticos não se aplicam sobre uma única frase $p$, mas sim sobre expressões do tipo $p / q$, compostas de duas frases. A expressão $\mathrm{O}(p / q)$ significa que $p$ descreve algo obrigatório, sob a condição $q$. Por exemplo, se $p$ afirma que João paga impostos e $q$ diz que João ganha acima do limite de isenção previsto em lei, então $\mathrm{O}(p / q)$ estabelece que, obrigatoriamente, João paga impostos, sob a condição de ganhar acima do limite de isenção. Sendo $s$ a frase João faz o bem e sendo $t$ uma tautologia, como $q \vee \sim q$, a expressão $\mathrm{O}(s / t)$ significa que João está obrigado a fazer o bem sob quaisquer circunstâncias, de vez que uma tautologia é sempre verdadeira. Nesses termos, a frase $\mathrm{O}(p / q)$ indica que a obrigação $p$ se caracteriza apenas sob 
a condição $q$, enquanto que $\mathrm{O}(s / t)$ afirma que $s$ é uma obrigação incondicional, pois vale sempre.

Em 1956, von Wright delineou um primeiro sistema de lógica deôntica diádica (von Wright, 1956). Em 1964, ele apresentou o seu Novo Sistema (New System), que foi corrigido, em 1965 (von Wright, 1964, 1965). O Novo Sistema, com a correção de 1965 , toma a expressão O(.../...) como primitiva, sendo que os espaços em branco devem ser preenchidos por fórmulas da lógica proposicional comum. Definitoriamente, $\mathrm{P}(p / q)$ equivale a $\sim \mathrm{O}(\sim p / q)$, sendo que a segunda ocorrência da negação, por razões sintácticas, deve darse imediatamente antes da variável $p . \mathrm{F}(p / q)$ tem a definição usual, como equivalente a $\sim \mathrm{P}(p / q)$. Na versão modificada de Føllesdal e Hilpinen (1971, p. 27), os axiomas do Novo Sistema (corrigido) são os seguintes:

$$
\begin{aligned}
& \text { B1. } \mathrm{O}(p \vee \sim p / r) \\
& \text { B2. } \sim[\mathrm{O}(p / t) \& \mathrm{O}(\sim p / t)] \\
& \text { B3. } \mathrm{O}(p \& q / r) \equiv[\mathrm{O}(p / r) \& \mathrm{O}(q / r)] \\
& \text { B4. } \mathrm{O}(p / r \vee s) \equiv[\mathrm{O}(p / r) \& \mathrm{O}(p / s)]
\end{aligned}
$$

O primeiro destes axiomas não consta no Novo Sistema, de 1964, sendo sugerido por Føllesdal e Hilpinen. Ele cinge-se a ditar uma obrigação tautológica $p \vee \sim p$, que vale sob $r$ ou sob qualquer outra condição. $\mathrm{O}$ axioma $\mathrm{B} 2$ nega que tanto $p$ quanto $\sim p$ possam ser obrigações absolutas. Segundo B3, se existe uma obrigação conjuntiva, sob a condição $r$, então cada membro da conjunção é obrigatório, sob $r$. O axioma B4 é típico deste sistema. Tentando dar-lhe caráter intuitivo, von Wright interpreta-o assim: a obrigatoriedade de que se feche uma janela, em caso de chuva ou trovão, equivale à obrigatoriedade de fechá-la, em caso de chuva e em caso de trovão (von Wright, 1971[1964], p. 110).

As regras de inferência do Novo Sistema (corrigido), na versão presente, são as seguintes:

Regra da substituição de uma variável por uma fórmula: Num axioma ou teorema, uma variável proposicional pode ser substituída por uma fórmula, desde que todas as ocorrências da variável sejam substituídas pela mesma fórmula.

Regra liberalizada do modus ponens: De $p$ e $p \supset q$ derive-se $q$. ( $p$ e $q$ representam fórmulas quaisquer, que não precisam ser teoremas.)

Regra da substituição por equivalência: Num axioma ou teorema, é possível substituir-se uma variável proposicional ou uma subfórmula molecular por fórmulas moleculares que lhe sejam equivalentes. 
Regra da substituição de variáveis por fórmulas atômicas deônticas: Se, numa tautologia da lógica comum, todas as ocorrências de uma variável proposicional são substituídas por uma fórmula atômica do tipo $\mathrm{O}(p / q)$, obtém-se um teorema.

Em 1970, Hansson desenvolveu uma forma adaptada de semântica dos mundos deonticamente perfeitos para a lógica diádica (Hansson, 1971[1970]). De um modo geral, no Novo Sistema (corrigido), os paradoxos da obrigação derivada, do compromisso e da obrigação reparadora não ocorrem. As relações entre frases deônticas expressas no sistema-padrão continuam a valer, mas como obrigações incondicionais. A frase do sistema-padrão $\mathrm{O}(p \supset q) \supset(\mathrm{O} p \supset$ $\mathrm{O} q)$, por exemplo, corresponde ao teorema $\mathrm{O}(p \supset q / t) \supset[\mathrm{O}(p / t) \supset \mathrm{O}(q / t)]$.

Um aspecto controverso do Novo Sistema (corrigido) diz respeito à noção de obrigações mutuamente contraditórias. O primeiro axioma do Novo Sistema de 1964 proibia obrigações contraditórias ( $p$ e $\sim p$ ), sob uma mesma condição $r$. Por exemplo, sob a condição de se ganhar certo ordenado $(r)$, não se pode ser obrigado a pagar e a não pagar impostos $(p$ e $\sim p)$. Na versão corrigida, a proibição de obrigações contraditórias restringe-se aos casos de obrigações incondicionais, válidas sob circunstâncias quaisquer $t$. Isto significa que, teoricamente, alguém poderia ter obrigações contraditórias, numa condição contingente $r$. Von Wright cita como exemplo o caso bíblico de Jefté, que prometeu sacrificar a Deus a primeira pessoa que passasse pelo pórtico da sua casa, desde que ele conseguisse derrotar os amonitas, inimigos do seu povo. Jefté venceu, mas quem primeiro passou pelo pórtico da casa, para saudá-lo festivamente, foi a sua única filha. Apesar de tudo, Jefté cumpriu sua promessa e sacrificou a filha (Juízes, 11, 29-40). Uma tal situação é chamada por von Wright de provação (predicament). Ela se verificaria quando o agente tivesse obrigações contraditórias (cumprir o prometido, não cumprir o prometido), sob a condição específica de ter feito o que não deveria (prometer um sacrifício humano). Von Wright admite isso como aceitável (von Wright, 1971[1964], p. 115-119).

A solução proposta por von Wright tem o inconveniente de ferir drasticamente nossas intuições deônticas, pois, como observam Føllesdal e Hilpinen, um código que imponha obrigações contraditórias, nas mesmas circunstâncias, é objetável. Parece correto admitir que prometer o proibido é fazer uma pseudopromessa que, como tal, não deve ser cumprida. Nessa linha de raciocínio, Føllesdal e Hilpinen propõem que o axioma B4 seja substituído por uma versão mais fraca, ou seja: 


$$
\text { B4'. [O }(p / r) \& \mathrm{O}(p / s)] \supset \mathrm{O}(p / r \vee s)
$$

B4' é aceitável, pois estabelece que se uma obrigação $p$ vige sob condições diversas $r$ e $s$, então ela vige sob a disjunção de tais obrigações.

\section{A lógica deôntica com dois tipos de frases}

$\mathrm{O}$ sistema-padrão e a lógica diádica aplicam os operadores $\mathrm{O}$ e $\mathrm{P}$ a expressões como $p$ ou $q$, por exemplo, que representam frases declarativas, verdadeiras ou falsas. Isso pode provocar uma dificuldade, pois os códigos de obrigações, como o Decálogo bíblico ou a Constituição da República, são conjuntos de imperativos, isto é, de comandos ou de ordens a serem cumpridas: Ama ao Senhor teu Deus (Decálogo), Paga teus impostos (Constituição da República, numa leitura livre). Por que os sistemas padrão e diádico ignoram os imperativos, apesar de estarem estes no próprio núcleo dos códigos de obrigações?

A resposta a tal questão reside numa característica importante das frases imperativas: elas não são verdadeiras nem falsas. Quando se diz a alguém: Fecha a porta, emiti-se um imperativo que pode ser obedecido ou não, mas que jamais será verdadeiro ou falso, pois ele não é uma descrição de qualquer estado de coisas, mas sim um simples comando comportamental.

Diante dessa característica dos imperativos, Jørgensen afirmou que uma lógica de tais frases seria impossível. Entretanto, ele reconheceu que imperativos mantêm entre si certas relações lógicas, pois eles podem ser mutuamente contraditórios, por exemplo (Jørgensen, 1937/1938). Essa dificuldade em entender o papel dos imperativos na argumentação deôntica é o assim chamado paradoxo de Jørgensen.

Os sistemas padrão e diádico contornaram o problema, interpretando $p, q$, etc. como expressões de estados de coisas, cuja realização é declarada obrigatória. Diante do mandamento Amarás ao Senhor teu Deus, o sistemapadrão entende $p$ como Os seres humanos amam a Deus, de modo que Op seja uma frase verdadeira ou falsa, capaz de descrever o mencionado comando. Por isso mesmo, sistemas padrão e diádico pertencem à lógica deôntica descritiva.

No sistema a ser exposto a seguir, essa estratégia é abandonada, em favor de uma lógica que lança mão de dois tipos de frases: declarativas, que são verdadeiras ou falsas, e imperativas, que não são uma coisa nem outra. Tal proposta foi elaborada por Hector-Neri Castañeda, um filósofo norte-americano, 
de origem guatemalteca. Ao longo dos anos 1950 e 1960, em inúmeros artigos, Castañeda desenvolveu e amadureceu suas idéias a respeito do assunto, até que as consolidou no livro Thinking and Doing - The Philosophical Foundations of Institutions, publicado em 1975 (Castañeda, 1975). Esse livro não se restringe à lógica deôntica. Como diz seu subtítulo, ele pretende ser uma investigação filosófica sobre instituições, em geral. A lógica deôntica é nele caracterizada num contexto mais amplo, visto que obrigações, permissões e proibições são institucionais. Castañeda, porém, parte de uma perspectiva mais ampla ainda. Ele afirma que o homem se relaciona com o mundo de duas maneiras: uma teórica e outra prática. A relação com o mundo é teórica, quando o homem tenta conhecê-lo, de algum modo. Tal relação é prática, quando o interesse humano concentra-se na manipulação de objetos. Quem procura conhecer a estrutura química do açúcar, por exemplo, relaciona-se teoricamente com tal substância. Ao final de uma pesquisa, ele poderá dizer $A$ fórmula do açúcar é $C_{12} H_{22} O_{11}$, sendo que tal frase é verdadeira. Entretanto, se o mesmo indivíduo quer adoçar o seu café e diz a alguém Passa-me o açúcar, por favor, ele tem outra relação com respeito à mesma substância. Agora ele quer manipulá-la, tendo em vista obter um resultado que corresponda ao seu paladar. Nestes exemplos, a primeira frase é declarativa, fruto de atitude teórica frente ao mundo, enquanto que a segunda é imperativa, que traduz um interesse prático.

A relação prática do homem frente aos objetos não se restringe aos imperativos. O mesmo indivíduo do exemplo anterior, ao verificar que lhe falta açúcar em casa, manifestará sua intenção de comprá-lo com uma frase do tipo: Amanhã, comprarei açúcar. Como simples manifestação de um propósito, tal frase não é verdadeira nem falsa.

Castañeda agrupa frases imperativas e manifestações de intenção numa mesma categoria, que ele chama de praticidades (practitions). Isso lhe permite construir um sistema com dois tipos de frases, que são as frases declarativas, de um lado, e as praticidades, de outro. As primeiras têm a ver com teoria, as demais relacionam-se com a prática (Castañeda, 1975, p. 43 et seq.).

Uma vez estabelecida essa diferenciação fundamental, Castañeda dá um passo adiante, estabelecendo a seguinte tese: os operadores deônticos, $\mathrm{O}, \mathrm{P}$ e F, aplicam-se a praticidades e não a frases declarativas ou a outras composições lingüísticas. $\mathrm{O}$ sistema que ele constrói admite expressões do tipo $\mathrm{O} A$ se, e somente se, $A$ representar uma praticidade, um imperativo, por exemplo. Se $A$ for uma frase declarativa, $\mathrm{O} A$ estará malformada.

Uma outra tese subjaz ao sistema que Castañeda elabora: da aplicação de um operador deôntico, $\mathrm{O}$ ou $\mathrm{P}$, sobre uma praticidade, resulta uma frase declarativa, que expressa o verdadeiro ou o falso (Castañeda, 1977, p. 44-45). 
Por fim, Castañeda postula que as obrigações e permissões ocorrem sempre num contexto institucional, que lhes dá sentido. Isto implica a indexação dos operadores, $\mathrm{O}_{i}, \mathrm{P}_{i}, \mathrm{~F}_{i}$, de modo a que se expresse sua conexão com as correspondentes instituições $i$, nas quais eles valem. Por exemplo, se $d$ representa o Decálogo, $c$ representa a Constituição da República, e $A, B$ representam, respectivamente, os imperativos Amarás ao Senhor teu Deus e Paga teus impostos, então, serão verdadeiras as fórmulas $\mathrm{O}_{d} A$ e $\mathrm{O}_{c} B$. A primeira diz que, consoante o Decálogo, é obrigatório amar a Deus. A segunda estabelece que, nos termos da Constituição, impostos devem ser pagos. Decálogo e Constituição são contextos institucionais (Castañeda, 1975, p. 1 et seq.)

Castañeda introduz o conceito de obrigação dominante pura (pure overriding ought). Isso é apenas a maneira de caracterizar um tipo de obrigação institucional que permita resolver conflitos entre deveres. Por exemplo, o Estado ateniense, ao condenar Sócrates, proibiu-o de ensinar. O filósofo, porém, entendia que ensinava por mandamento dos deuses! A quem obedecer, ao Estado ou aos deuses? Obviamente, diante de tal conflito, Sócrates escolheu o seu dever para com os deuses, desobedecendo ao Estado. Nesse caso, a obrigação para com os deuses $\left(\mathrm{O}_{d^{\prime}}\right)$ é dominante, com respeito à obrigação $\left(\mathrm{O}_{e}\right)$ para com o Estado. Na linguagem sugerida por Castañeda, $\mathrm{O}_{1}$ será uma obrigação dominante pura, que domina qualquer outra (Castañeda, 1975, p. 30 et seq.; 1977, p. 43 et seq.).

Sejam $p, q, r, \ldots$ frases declarativas. Sejam $A, B, \ldots$ praticidades. Sejam $p *$ e $q *$ frases declarativas ou praticidades. Os axiomas da lógica deôntica proposicional com dois tipos de frases são os seguintes:

C1. $\mathrm{O}_{i} A \supset \mathrm{C}_{i}$, sendo $\mathrm{C}_{i}$ a conjunção de todas as condições necessárias para a obrigatoriedade . $^{\text {. }}$

C2. $p^{*}$, se $p^{*}$ tem a forma de uma tautologia da lógica proposicional.

C3. $\mathrm{O}_{i} A \supset \sim \mathrm{O}_{i} \sim A$

C4. $\mathrm{O}_{1} A \supset A$. Este axioma substitui o anterior, num sistema de obrigação dominante.

Na verdade, tais axiomas definem uma infinidade de sistemas possíveis, que variam consoante a instituição $i$. Para cada instituição, há condições de obrigatoriedade. De acordo com o axioma $\mathrm{C} 1$, se $A$ é obrigatória, em $i$, então as respectivas condições para tanto estão estabelecidas. $\mathrm{O}$ axioma $\mathrm{C} 2$ postula as tautologias do cálculo proposicional, que também podem ser formuladas com o auxílio de praticidades. C3 é o Princípio de Permissão: o que é obrigatório, 
em $i$, é permitido, em $i$. Segundo $C 4$, dá-se $A$, se $A$ for obrigatória nos termos da obrigação dominante pura.

As regras de inferência deste sistema são as seguintes:

Regra do modus ponens para dois tipos de frases: De $p *$ e $p * \supset q *$ derivese $q *$.

Regra da introdução do operador $\mathrm{O}_{i}$ : se a frase $\left(p \& A_{1} \& \ldots \& A_{n}\right) \supset B$ for um teorema, num sistema deôntico $\mathrm{D}_{i}$, então $\left(p \& \mathrm{O}_{i} A_{1} \& \ldots \& \mathrm{O}_{i} A_{n}\right) \supset$ $\mathrm{O}_{i} B$ também será teorema, em $i(n \geq 0)$.

As seguintes frases são alguns dentre os teoremas deste sistema:

- $\left(\mathrm{O}_{i} A \& \mathrm{O}_{i} B\right) \equiv \mathrm{O}_{i}(A \& B)$

- $\mathrm{O}_{i}(A \supset B) \supset\left(\mathrm{O}_{i} A \supset \mathrm{O}_{i} B\right)$

- $\left(p \& \mathrm{O}_{i} A\right) \equiv \mathrm{O}_{i}(p \& A)$

- $\left(p \supset \mathrm{O}_{i} A\right) \equiv \mathrm{O}_{i}(p \supset A)$

- $\mathrm{O}_{i}(A \supset p) \equiv\left(\mathrm{P}_{i} A \supset p\right)$

Tais teoremas são versões de princípios válidos nos sistemas padrão e diádico. Entretanto, neles os operadores $\mathrm{O}_{i}$ ou $\mathrm{P}_{i}$ estão sempre associados a praticidades $A, B$. O segundo teorema, por exemplo, assevera que, dada a obrigatoriedade ${ }_{i}$ de $A \supset B$, então a obrigatoriedade ${ }_{i}$ de $A$ implica a obrigatoriedade $_{i}$ de $B$ (Castañeda, 1975, p. 263-264; 1977, p. 54-55).

A presente apresentação do sistema de Castañeda cinge-se ao cálculo proposicional, no qual as idéias básicas do autor já se articulam. Mas tal sistema é amplo e complexo, abrangendo toda a lógica de $1^{\mathrm{a}}$ ordem, com inclusão da identidade, além de um vasto repertório filosófico-fenomenológico subjacente. Uma vez caracterizado o sistema, na sua plenitude, é fácil para Castañeda eliminar todos os paradoxos deônticos, de modo simples e de um só golpe (Castañeda, 1981). Sua estratégia é semelhante àquela empregada por Russell, em 1908, quando este eliminou o paradoxo que ocorria no sistema de Frege e que tinha a ver com a auto-referência. Russell, reelaborou o tipo de linguagem até então empregado pelos lógicos, de tal modo que o paradoxo em pauta tornou-se um mero erro de sintaxe. O mesmo faz Castañeda: na tradução da linguagem natural para a linguagem formal, as conexões sintáticas estabelecidas nos sistemas por ele propostos travam o surgimento de expressões, a partir das quais os paradoxos poderiam emergir. Em particular, o paradoxo da obrigação reparadora não ocorre na lógica deôntica com dois tipos de frases (Tomberlin, 1986). 
O complexo sistema proposto por Castañeda faz amplo uso da fenomenologia. Um discípulo seu, Harry J. Gensler, com idéias filosóficas diferentes, esboça um sistema de ética formal, que, entretanto, ainda carece de uma caracterização mais precisa (Gensler, 1996; 1998).

\section{Lógica deôntica das ações}

No seu ensaio de 1951, von Wright emprega frases como $\mathrm{O} p$ e $\mathrm{P} q$, nas quais $p$ e $q$ representam classes de ações e não variáveis proposicionais. Se $q$, por exemplo, simboliza a ação de fumar, $\mathrm{P} q$ significa que é permitido fumar. Ora, como ações não são verdadeiras nem falsas, objeta-se contra von Wright que expressões como $\mathrm{P} q \vee \mathrm{P} \sim q$ estariam malformadas, pois a negação deveria ocorrer antes de uma frase declarativa e jamais antes de símbolos de outro tipo. A objeção é procedente, o que leva os lógicos a construirem o sistemapadrão, no qual os operadores $\mathrm{O}$ e $\mathrm{P}$ são mantidos, mas expressões como $p$ e $q$ são interpretadas como frases declarativas.

O ensaio de 1951 é uma tentativa de construir uma lógica normativa da ação, ou seja, uma lógica do dever-fazer (ought-to-do, Tunsollen). Em contraposição a ele, o sistema-padrão e a lógica diádica são lógicas do deverser (ought-to-be, Seinsollen), na medida em que descrevem estados de coisas cuja realização seja obrigatória ou permitida. Apesar do rumo que os sistemas deônticos tomaram em direção ao dever-ser, a idéia de uma lógica normativa da ação nunca foi abandonada. A partir dos anos 80 do século XX, estudos deste último tipo tornaram-se mais freqüentes, sobretudo no contexto da assim chamada lógica dinâmica, que investiga os estados de um sistema qualquer. Na lógica dinâmica, a ação é entendida como modificação do mundo, de modo que sucessivas ações sejam interpretadas como diversos estados deste último (Hilpinen, 2001, p. 173-174; Goldblatt, 1987). No seu exercício profissional, o médico age de modo a produzir uma passagem de um estado $e_{1}$, no qual o paciente está enfermo, para um outro estado $e_{2}$, no qual ele esteja saudável.

Preliminarmente, ações podem ser simbolizadas por meio de letras $A$, $B, C, \ldots$ Estas são termos de ações. É possível aplicar conectivas de ações sobre tais termos, que, em alguns casos, são análogas às conectivas da lógica proposicional. As seguintes convenções podem ser estabelecidas, entre outras:

D1. $A+B$ : fazer $A$ e/ou $B$

D2. $A \bullet B$ : fazer $A$ e $B$, conjuntamente

D3. Om $A$ : omitir $A$ (Om $A$ aplica-se a ações que não sejam exemplos de A.) 
D4. $A ; B$ : fazer $A$ e depois $B$

D5. $A^{n}$ : fazer $A, n$ vezes

D6. $\Theta$ : fazer nada

Uma teoria da ação trabalha sobre uma infinidade de estados do mundo $e_{0}$, $e_{1}, e_{2}, \ldots$ A relação de acessibilidade ou o processo de passagem de um estado a outro pode ser simbolizado por Pass. Seja Pass o conjunto das passagens que comecem com o estado $e$. O desenvolvimento de uma teoria especificamente deôntica da ação exigirá a subdivisão de $e_{0}, e_{1}, e_{2}, \ldots$ em duas classes, sendo que uma conterá passagens aceitáveis ou legais e a outra conterá passagens inaceitáveis ou ilegais. Seja $\operatorname{Leg}_{e}$ o conjunto de seqüências das passagens legais começadas com a situação $e$. Seja $\mathrm{Ile}_{e}$ o conjunto de seqüências das passagens ilegais começada com $e$. Intuitivamente, a união desses conjuntos será uma totalidade na qual estarão todas as seqüências de estados iniciadas com $e$, ou seja:

D7. $\operatorname{Leg}_{e} \cup \mathrm{Ile}_{e}=$ Pass $_{e}$

Além disso, o conjunto de seqüências de passagens legais nada partilha com o conjunto de seqüências de passagens ilegais, ou seja:

D8. $\operatorname{Leg}_{e} \cap \mathrm{Ile}_{e}=\varnothing$

Por fim, admite-se que sempre haja uma saída legal de cada situação, de modo que, sendo $\mathrm{M}$ o conjunto dos mundos ou situações possíveis e sendo $e$ um estado, deve valer:

D9. Para todo $e \in \mathrm{M}: \operatorname{Leg}_{e} \neq \varnothing$

Neste tipo de contexto semântico, seja I uma interpretação que associe uma ação $A$ às sua realizações, nos mundos possíveis. $\mathrm{I}_{e}(A)$ deve representar, então, o conjunto das realizações de ações originadas a partir de $e$. Com esses elementos, é possível definir os operadores deônticos de proibição permissão e obrigação. Isso é feito da seguinte maneira:

D10. F $A$ é uma frase verdadeira, no estado $e$, se, e somente se, $\mathrm{I}_{e}(A) \subseteq$ $\mathrm{Ile}_{e}$

D11. P $A$ é uma frase verdadeira, no estado $e$, se, e somente se, $\mathrm{I}_{e}(A) \cap$ $\operatorname{Leg}_{e} \neq \varnothing$ 
D12. O $A$ é uma frase verdadeira, no estado $e$, se, e somente $\operatorname{se}, \mathrm{I}_{e}(\mathrm{Om} A)$ $\subseteq \mathrm{Ile}_{e}$

Consoante $\mathrm{D} 10$, a ação $A$ é proibida, precisamente, quando cada realização possível de $A$, no estado $e$, for ilegal. Consoante D11, a ação $A$ é permitida se, e somente se, $A$ pode ser legalmente realizada. Consoante D12, a ação $A$ é obrigatória se, e somente se, for ilegal omiti-la (Hilpinen, 2001, p. 173175). Dessa maneira, os operadores deônticos são definidos com o auxílio do conceito de ação.

No tipo de linguagem ora apresentada, é possível não apenas representar ações $(A, B, C, \ldots)$, mas também caracterizar frases declarativas que as descrevem. Para tanto, emprega-se um operador intensional que é Do, o operador de ação. Sendo $a$ uma expressão que represente um agente como João, por exemplo, e $p$ uma variável que represente uma frase verdadeira ou falsa, como A porta é fechada, $\operatorname{Do}(a, p)$ lê-se da seguinte maneira: João fecha a porta, ou João toma medidas para que a porta seja fechada. De um modo geral, $\operatorname{Do}(a, p)$ lê-se como $a$ faz $p$, ou $a$ toma medidas para que $p$ aconteça. Correspondentemente, as seguintes leituras estão corretas:

$\operatorname{Do}(a, p): a$ faz $p$

$\sim \operatorname{Do}(a, p): a$ não faz $p$

$\operatorname{Do}(a, \sim p): a$ faz não- $p$

$\sim \operatorname{Do}(a, \sim p): a$ não faz não- $p$

Graças ao emprego dessas expressões, é possível que as diversas relações deônticas entre dois agentes $a$ e $b$ sejam definidas. Seja $\mathrm{R}(a, b)$ uma frase que expresse uma relação entre $a$ e $b$. Combinando-se o operador Do com $\mathrm{O}$ e $\mathrm{P}$, obtém-se:

$$
\begin{aligned}
& \text { D13. } \mathrm{ODo}[b, \mathrm{R}(a, b)] \\
& \mathrm{D} \text { 14. } \sim \mathrm{ODo}[a, \sim \mathrm{R}(a, b)] \equiv \mathrm{P} \sim \operatorname{Do}[a, \sim \mathrm{R}(a, b)] \\
& \mathrm{D} 15 . \sim \mathrm{O} \sim \operatorname{Do}[a, \mathrm{R}(a, b)] \equiv \operatorname{PDo}[a, \mathrm{R}(a, b)] \\
& \mathrm{D} 16 . \mathrm{O} \sim \operatorname{Do}[b, \mathrm{R}(a, b)]
\end{aligned}
$$

As condições D13-D16 definem quatro tipos de direitos, segundo o ponto de vista do agente $a$. Se, por exemplo, $\mathrm{R}(a, b)$ significa que $a$ recebe ajuda de $b$, então D13-D16 podem ser interpretadas sem dificuldade. D13 diz que $b$ tem a obrigação de tomar medidas no sentido de que $a$ receba a sua ajuda. Portanto, $a$ tem a pretensão no sentido de que $b$ zele para que $a$ receba ajuda de $b$. D14 
descreve a liberdade de $b$, no sentido de não tomar medidas para que $a$ seja ajudado por $b$. Assim sendo, é permitido a $b$ deixar de tomar medidas para que $a$ seja ajudado por $b$. D15 diz que $a$ tem o poder (ou a permissão) de tomar medidas para ser ajudado por $b$. D16 diz que $a$ tem a imunidade, no sentido de $b$ não tomar medidas para que $a$ seja ajudado por $b$. Com isso, estão definidos os seguintes conceitos que relacionam dois agentes: pretensão, liberdade, poder e imunidade. Substituindo-se $\mathrm{R}(a, b)$ por $\sim \mathrm{R}(a, b)$, outras quatro condições são obtidas. Elas representam, respectivamente, a contra-pretensão, a contraliberdade, o contra-poder e a contra-imunidade. Conjugando-se esses oito tipos de conceitos, é possível que se obtenha um total de $2^{8}=256$ relações entre dois agentes quaisquer. Eliminando-se eventuais inconsistências, resulta um número de 26 combinações de direitos entre esses dois agentes (Kanger, 1971[1957]; Kanger e Kanger, 1966, apud Hilpinen, 2001, p. 178).

A lógica da ação traz significativas contribuições filosóficas, entre as quais a tese de John F. Horty, segundo a qual a lógica do dever-ser não é mera variação da lógica do dever-fazer (Horty, 2001). Esse tipo de lógica pode ser combinado com aquilo que se chama lógica dinâmica, cujo interesse se concentra em eventos e nas suas mudanças. O resultado é uma lógica dinâmica voltada para ações e eventos, que é uma das mais intensas e promissoras direções de pesquisa na lógica deôntica contemporânea (Lindström; Segerberg, 2007, p. 1197-1209).

\section{A lógica corrigível}

Desde 1980, aproximadamente, vem sendo desenvolvida uma forma de lógica cujas aplicações ao raciocínio normativo são bastante relevantes. Trata-se da lógica deôntica corrigível (defeasible deontic logic). Uma regra é corrigível se ela admite exceções. Por exemplo, a frase Todo pássaro voa pode ser entendida como uma regra de ampla aplicação a casos singulares, mas que tem exceções, na medida em que pingüins são pássaros que não voam. Correspondentemente, uma lógica deôntica corrigível é um sistema que contém regras desse tipo. $\mathrm{O}$ grande interesse que ela possa ter para o trabalho do filósofo moral ou do jurista repousa, sobretudo, no facto de que sistemas normativos contenham regras com exceções, exceções de exceções, etc. Matar é proibido, mas matar em legítima defesa é permitido e matar na guerra é obrigatório.

A lógica de $1^{\mathrm{a}}$ ordem usual é monotônica, no seguinte sentido: o acréscimo de uma premissa adicional a um argumento válido resulta num novo argumento válido. Em contraposição a isso, num sistema lógico não-monotônico, uma nova premissa pode envolver perda de validade, na medida em que ela traga 
informações que não mais sustentem a respectiva conclusão. Em geral, um sistema deôntico corrigível deve ser não-monotônico.

Há vários tipos de sistemas deônticos corrigíveis, sendo significativas as diferenças existentes entre eles, sobretudo em função de distintas concepções filosóficas subjacentes (Nute (Ed.), 1997). Em qualquer caso, porém, um sistema deôntico corrigível tem de hierarquizar normas e estabelecer regras para a sua aplicação. Nos sistemas legais, por exemplo, a lei nacional tem precedência sobre a lei local, de tal forma que uma pode bloquear a aplicação da outra. Por outro lado, dadas regras de um mesmo tipo, a mais específica deve bloquear a mais geral. Um sistema de regras de etiqueta, por exemplo, pode conter os seguintes itens: 1. Tu deves evitar comer com as mãos; 2. Tu deves comer pão com as mãos. Essas regras não se contradizem, pois o agente tratará o pão como caso excepcional que foge à regra 1 (Horty, 1997, p. 35).

A lógica deôntica corrigível enfrenta o problema de tratar regras cuja hierarquização é problemática e cuja aplicação a casos particulares pode implicar contradição. Assim, por exemplo, as frases Professores universitários são dotados de espírito crítico e Fanáticos religiosos não são dotados de espírito crítico são asserções mutuamente independentes. Suponha-se, porém, que João seja ambos, professor universitário e fanático religioso. Concluise daí que ele seja e não seja dotado de espírito crítico? Não! As frases em pauta são regras corrigíveis, que não podem ser simultaneamente aplicadas a casos particulares. Portanto, é preciso que a aplicação de uma delas bloqueie a aplicação da outra, sob pena de contradição. Como isto pode ser feito? Uma das possibilidades, grosso modo, é a seguinte: o conjunto de frases \{João é professor universitário, João é fanático religioso $\}$ é tomado como uma classe de informações básicas. Sobre tal conjunto é aplicada a regra relativa a professores, daí derivando-se uma extensão na qual se diz que João é dotado de espírito crítico. Automaticamente, a regra relativa a fanáticos é bloqueada, nesta extensão. Sobre o mesmo conjunto, aplica-se a regra relativa a fanáticos e bloqueia-se a outra. Daí resulta uma segunda extensão, na qual se diz que João não é dotado de espírito crítico. Dessa maneira, evita-se uma asserção contraditória. Cada uma das mencionadas extensões é consistente, mas as frases nelas deduzidas são corrigíveis.

A elaboração de uma linguagem e de um conjunto de normas para tal sistema é complexa e pede hierarquização, até mesmo das regras formais clássicas. O assim chamado modus ponens factual ( $p, p \supset q \therefore q$ ), por exemplo, deve ter precedência de aplicação sobre o modus ponens deôntico $(\mathrm{O} p, \mathrm{O}(p$ $\supset q) \therefore \mathrm{O} q$ ). As regras de precedência são fundamentais, pois a ordem de aplicação determina a conclusão a ser inferida (Nute; Xiaochang, 1997). 
No presente contexto, o problema dos dilemas morais ganha especial relevância. Como se sabe, o agente enfrenta um dilema moral se ele vive um verdadeiro conflito de obrigações. $\mathrm{O}$ exemplo freqüentemente citado remonta a uma conferência de Sartre, na qual este fala de um jovem francês torturado entre obrigações inconciliáveis. De um lado, ele sentia-se no dever de unir-se à resistência ao inimigo alemão. De outro, ele entendia que era sua obrigação permanecer ao lado da mãe, para poder prestar-lhe assistência.

Há um debate sobre a existência de dilemas morais. Autores como Bernard Williams, por exemplo, admitem que haja tais dilemas, mas advogam que eles exigem o abandono de certas leis deônticas (Williams, 1973[1965], p. 179). Mas autores como Nute recusam a tese da existência de verdadeiros dilemas morais, ao menos no caso de obrigações prima facie (Nute, 1997, p. 311).

Uma interessante abordagem de dilemas morais é o trabalho de Kooms e Seung, no qual o problema é tratado sob a perspectiva de um sistema lógico corrigível com três valores de verdade: verdadeiro (V), falso (F) e indeterminado (I). Nesse sistema, cada frase tem apenas um valor de verdade, mas esse valor pode variar, se a mesma frase for corrigivelmente deduzida, em extensões diferentes, a partir de um mesmo conjunto de informações. Nesses termos existem os seguintes conjuntos de possibilidades: 1. $\{\mathrm{V}\} ; 2 .\{\mathrm{F}\} ; 3$. $\{\mathrm{I}\}$; 4. $\{\mathrm{V}, \mathrm{I}\} ; 5 .\{\mathrm{F}, \mathrm{I}\} ; 6 .\{\mathrm{V}, \mathrm{F}\} ; 7 .\{\mathrm{V}, \mathrm{F}, \mathrm{I}\}$. Nos três primeiros casos, uma frase tem um mesmo valor (verdadeiro ou falso ou indeterminado), nas diversas extensões. No quarto caso, uma frase é verdadeira em uma extensão e é indeterminada, em outra. No quinto caso, a frase é falsa e é indeterminada. No sexto caso, a frase é verdadeira em uma extensão e é falsa, em outra. No último caso, a frase assume os três valores, em extensões diversas. O sexto e o último caso são característicos de dilemas morais.

Kooms e Seung ilustram a sua análise com exemplos, sendo que o mais interessante é o de Churchill, num episódio de 1940. Eram os meses da Batalha da Inglaterra. O serviço secreto britânico conseguira decifrar códigos alemães. Logo foi descoberto um plano para bombardear uma área densamente povoada, em Coventry. Como reagir diante de tal situação? A área poderia ser evacuada, mas com isso os inimigos saberiam que os britânicos conheciam os seus códigos, o que anularia importantes esforços de guerra. Em tal situação, Churchill não evacuou a região ameaçada. Coventry foi pesadamente bombardeada, muitos morreram, mas o segredo militar foi preservado, o que possibilitou futuras vitórias.

Seja $\Rightarrow$ uma representação do conectivo condicional corrigível. Em termos gerais, as regras que se aplicam ao caso seriam as seguintes: 
E1. Salva vidas inocentes \& O agente é comandante $\Rightarrow$ Está certo. E2. Faz perigar esforços de guerra, de modo grave \& O agente é comandante $\Rightarrow$ Não está certo.

Os fatos relevantes podem ser descritos da seguinte maneira:

E3. a) A evacuação da área salva vidas inocentes; b) $O$ agente é comandante; c) A evacuação da área faz perigar esforços de guerra, de modo grave.

Com o auxílio da regra E1 e dos itens E3a) e E3b), deriva-se uma extensão, na qual se afirma que a evacuação da área é a medida correta. Graças à regra E2 e aos itens E3b) e E3c), deriva-se uma segunda extensão, na qual se diz que a evacuação da área não é a medida correta. Considerando-se ambas as extensões, segue-se daí que a tese de que a área deva ser evacuada corresponde à valoração $\{\mathrm{V}, \mathrm{F}\}$. Nesse caso, segundo Koons e Seung, o agente tem de decidir solitariamente, pois o discurso ético não o pode ajudar. Esse seria o verdadeiro dilema, no qual todo o peso da decisão recai sobre quem escolhe.

Em princípio, seria possível agregar uma norma adicional, de modo a permitir compensações aos prejudicados, ou aos seus parentes. Tal norma seria aplicável mesmo que o agente conseguisse justificar o seu procedimento. Ela seria a seguinte:

E4. Age de modo certo \& Não houve evacuação da área $\Rightarrow O$ agente deve compensação.

À conclusão de que deva haver compensação corresponderá a valoração $\{\mathrm{V}, \mathrm{I}\}$. Embora esta seja ambígua, ela direcionará o agente a compensar os prejudicados (Koons; Seung, 1997, p. 214-215).

A lógica deôntica corrigível é promissora a ponto de o filósofo moral $\mathrm{H}$. Lauener afirmar ser ela o tipo de sistema formal adequado para subjazer ao raciocínio ético (Lauener, 2001).

\section{Obrigação e necessidade}

Alguns lógicos deônticos retomam certas teses de Leibniz para definir as relações entre obrigação e necessidade. Segundo Leibniz, permitido (licitum) seria aquilo que é possível a um bom homem fazer; obrigatório (debitum) 
seria o que é necessário a um bom homem fazer (Leibniz, 1930, apud Hilpinen 2001, p. 159).

Nessa linha de pensamento, Stig Kanger define obrigação da seguinte maneira:

- $\mathrm{O} p={ }_{\mathrm{df}} \mathrm{L}(\mathrm{Q} \supset p)$

Nessa definição, Q é uma constante proposicional que significa aquilo que a moral exige. Portanto, $p$ será obrigatório se, e somente se, necessariamente, $\mathrm{o}$ que a moral exige implicar $p$. Correspondentemente, o conceito de permissão terá a seguinte definição:

$$
\text { - } \mathrm{P} p={ }_{\mathrm{df}} \mathrm{M}(\mathrm{Q} \& p)
$$

Portanto, permitido será algo que, possivelmente, seja feito de modo conjunto com aquilo que a moral exige.

Se L e M são operadores que satisfaçam às condições do sistema modal elementar $\mathbf{K}$ e se a frase MQ (O que a moral exige é possível) for tomada como axioma, então os axiomas do sistema-padrão podem ser derivados. Nesse caso, os operadores deônticos $\mathrm{O}$ e $\mathrm{P}$ terão sido reduzidos aos operadores $\mathrm{L}$ e M. De modo mais geral: a lógica deôntica terá sido reduzida à lógica modal (Kanger, 1971[1957]; Føllesdal; Hilpinen, 1971, p. 19-20; Hilpinen, 2001, p. 159-162).

Uma outra forma de reduzir a lógica deôntica à lógica modal é sugerida por Alan Ross Anderson, por meio da seguinte definição:

$$
\text { - } \mathrm{O} p={ }_{\mathrm{df}} \mathrm{L}(\sim p \supset \mathrm{S})
$$

S é uma constante proposicional que simboliza a ocorrência de algo ruim. No caso, $p$ será obrigatório se, e somente se, necessariamente, a omissão de $p$ implicar algo de ruim, como o surgimento de um mal no mundo ou a punibilidade do agente, por exemplo. A correspondente definição do operador P seria:

$$
\text { - } \mathrm{P} p={ }_{\mathrm{df}} \mathrm{M}(p \& \sim \mathrm{S})
$$

Portanto, $p$ é permitido se, e somente se, é possível que $p$ seja realizado, sem que algo ruim aconteça. 
Se L e P satisfazem às condições do sistema $\mathbf{K}$, e se a fórmula LS (Não é necessário que aconteça algo de ruim) for tomada como axioma, então, com o auxílio das definições propostas por Anderson, os axiomas do sistema-padrão são deriváveis. Também dessa forma, a lógica deôntica padrão reduz-se à lógica modal elementar. $\mathrm{Se} \sim \mathrm{Q}$ for equivalente a $\mathrm{S}$, as definições de Kanger e Anderson serão igualmente equivalentes.

As mencionadas reduções da lógica deôntica à lógica modal alética são controversas, mesmo porque expressões como o que a moral prescreve ou algo ruim acontece escondem conteúdos deônticos. Além disso, a pretensão de se reduzir a lógica deôntica à lógica modal alética pode envolver a falácia naturalista, na medida em que signifique reduzir o dever-ser a estados de coisas (de Greef, 2003, p. 403). Porém, as propostas de Kanger e Anderson servem para que se distinga o significado de obrigação no Direito, de um lado, e na Moral, de outro. Talvez seja essa a razão por que von Wright sugere que a constante S seja entendida como imputabilidade (liability), pois, juridicamente, o agente que não cumpre a sua obrigação pode ser punido (von Wright, 1969, p. 93, apud Føllesdal e Hilpinen, 1971, p. 20). Ora, como a obrigação moral não envolve imputabilidade, cabe esclarecer o que seja obrigação, no discurso do eticista.

\section{A tendência atual}

Durante mais de cem anos, os matemáticos produziram os principais resultados relativos à lógica contemporânea. $\mathrm{O}$ fundador desta última - Gottlob Frege - era matemático, tal como Kurt Gödel, o autor do célebre resultado que traz o seu nome, demonstrado em 1931. Desde a segunda metade do século $\mathrm{XX}$, entretanto, vem sendo crescente o papel dos especialistas em ciências da computação no desenvolvimento da lógica. No caso especial da lógica deôntica, é inegável o interesse filosófico que, por várias décadas, motivou os teóricos da área, interessados em esclarecer conceitos e em elaborar sistemas normativos úteis ao filósofo e ao jurista. Porém, cada vez mais, a lógica deôntica vem sendo objeto de pesquisas de tipo algébrico, por apresentar características interessantes para diversos campos da computação. Mesmo nos casos de textos produzidos por autores que se esforçam por preservar algo da intuição filosófica, os aspectos computacionais acabam por prevalecer (p. ex., Antonelli, 2005). É possível que a tendência em direção às aplicações técnicas dos sistemas deônticos se torne univocamente predominante. 


\section{Referências}

ANTONELLI, G. A. Grounded Consequence for Defeasible Logic. New York: Cambridge University Press, 2005.

CASTAÑEDA, H.-N. Thinking and Doing: The Philosophical Foundations of Institutions. Dordrecht: D. Reidel Publishing Company, 1975.

CASTAÑEDA, H.-N. The Twofold Structure and the Unity of Practical Thinking. In: A. CONTE et al. (Ed.). Deontische Logik und Semantik. Wiesbaden: Athenaion, 1977.

CASTAÑEDA, H.-N. The Paradoxes of Deontic Logic: The Simplest Solution to All of Them in One Fell Swoop. In: HILPINEN, R. (Ed.). New Studies in Deontic Logic: Norms , Actions and the Foundations of Ethics. Dordrecht: D. Reidel Publishing Company, 1981. p. 37-86.

CHISHOLM, R. M. Contrary to Duty Imperatives and Deontic Logic. Analysis, 24, p. 33-36, 1963.

DE GREEF, J. Lógica deôntica. In: CANTO-SPERBER, M. (Org.). Dicionário de ética e filosofia moral. Tradução de Ana Maria Ribeiro-Althoff et al. São Leopoldo: UNISINOS. v. 1. Versão original: Dictionaire d'éthique et de philosophie morale. Parios: PUF, 2003.

FØLLESDAL, D.; HILPINEN, R. Deontic Logic: An Introduction. In: HILPINEN, R. (Ed.). Deontic Logic: Introductory and Systematic Readings. Dordrecht: D. Reidel Publishing Company, 1971. p. 1-38.

FORRESTER, J. Wm. Being Good \& Being Logical: Philosophical Groundwork for a New Deontic Logic. Armonk (N.Y.)/London (England): M.E. Sharpe, 1996.

GENSLER, H.J. Formal Ethics. London/New York: Routledge, 1996.

GENSLER, H.J. Ethics: A Contemporary Introduction. London/New York: Routledge, 1998.

GOLDBLATT, R. Logics of Time and Computation. Stanford: CSLI, 1987.

HANSON, B. An Analysis of Some Deontic Logics. In: HILPINEN, R. (Ed.). Deontic Logic: Introductory and Systematic Readings. Dordrecht: D. Reidel Publishing Company, 1971[1970]. p. 121-147.

HILPINEN, R. (Ed.). Deontic Logic: Introductory and Systematic Readings. Dordrecht: D. Reidel Publishing Company, 1971.

HILPINEN, R. (Ed.). New Studies in Deontic Logic: Norms, Actions and the Foundations of Ethics. Dordrecht: D. Reidel Publishing Company, 1981.

HILPINEN, R. Deontic Logic. In: GOBLE, L. (Ed.). The Blackwell Guide to Philosophical Logic. Oxford: Blackwell, 2001. p. 159-182.

HINTIKKA, J. Quantifiers in Deontic Logic. Societas Scientiarum Fennica Commentationes Humanarum Litterarum, Helsinki, 23, p. 4, 1957.

HINTIKKA, J. Deontic Logic and its Philosophical Morals. In: HINTIKKA, J. Models for Modalities: Selected Essays. Dordrecht: D. Reidel Publishing Company, 1970. p. 184-214. 
HORTY, J. Nonmonotonic Foundation for Deontic Logic. In: NUTE, D. (Ed.). Defeasible Deontic Logic. Dordrecht: Kluwer Academic Publishers, 1997. p. 17-44. HORTY, J. Agency and Deontic Logic. New York: Oxford University Press, 2001. JØRGENSEN, J. Imperatives and Logic. Erkenntnis, 7, p. 288-296, 1937-1938.

KANGER, S.; KANGER, L. Rights and Parliamentarism. Theoria, 32, p. 85-115, 1966.

KANGER, S. New Foundations for Ethical Theory. In: HILPINEN, R. (Ed.). Deontic Logic: Introductory and Systematic Readings. Dordrecht: D. Reidel Publishing Company, 1971[1957]. p. 36-58.

KANT, I. Grundlegung zur Metaphysik der Sitten. In: Kants Werke, IV, Akademie Textausgabe. Berlin: Walter de Gruyter, 1968 [1785]. p. 385-463.

KNUUTTILA, S. The Emergency of Deontic Logic in the Fourteenth Century. In: HILPINEN, R. (Ed.). New Studies in Deontic Logic: Norms, Actions and the Foundations of Ethics. Dordrecht: D. Reidel Publishing Company, 1981. p. 225-248. 1981.

KOONS, R.C.; SEUNG, T.K. Defeasible Reasoning and Moral Dilemmas. In: NUTE, D. (Ed.) Defeasible Deontic Logic. Dordrecht: Kluwer Academic Publishers, 1997. p. 205-222.

KRIPKE, S. Semantical Analysis of Modal Logic I: Normal Modal Propositional Calculi. Zeitschrift für mathematische Logik, 9, (1963a), p. 67-96.

KRIPKE, S. Semantical Considerations on Modal Logic", Proceedings of a Colloquium on Modal and Many-Valued Logics, Acta Philosophica Fennica, 16, p. 83-94. $1963 \mathrm{~b}$.

LAUENER, H. Ethik des Methodologischen Humanismus: Kritische Bemerkungen zur Relativität von Normen und zum Pluralismus von Systemen der Moral. Erkenntnis, 54, n. 1, p. 77-103, 2001.

LEIBNIZ, G.W. Elementa iuris naturalis. In: LEIBNIZ, G.W. Sämtliche Schriften und Briefe, Sechste Reihe: Philosophische Schriften, Bd. 1. Darmstadt: Otto Reichel Verlag, 1930. p. 431-485.

LINDSTRÖM, S.; SEGERBERG, K. Modal Logic and Philosophy. In: BLACKBURN, P.; van BENTHEM, J.; WOLTER, F. (Ed.). Handbook of Modal Logic. Amsterdam: Elsevier, 2007. p. 1149-1214.

MALLY, E. Grundgesetze des Sollens: Elemente der Logik des Willens. Graz: Leuchner \& Lubensky, 1926.

MARCISZEWSKI, W. (Ed.). Dictionary of Logic as Applied in the Study of Language: Concepts, Methods, Theories. The Hague: Martinus Nijhoff Publishers, 1981.

NUTE, D.; XIAOCHANG, Y. Introduction. In: NUTE, D. (Ed.). Defeasible Deontic Logic. Dordrecht: Kluwer Academic Publishers, 1997. p. 1-16.

NUTE, D. (Ed.) Defeasible Deontic Logic. Dordrecht: Kluwer Academic Publishers, 1997.

NUTE, D. Apparent Obligation. In: NUTE, D. (Ed.). Defeasible Deontic Logic. Dordrecht: Kluwer Academic Publishers, 1997. p. 287-316. 
PRIOR, A. Formal Logic. $2^{\text {nd }}$ ed. Oxford: Oxford University Press, 1962.

ROSS, A. Imperatives and Logic. Theoria, 7, p. 53-71, 1941.

TOMÁS DE AQUINO, Santo. Suma teológica. Tradução de Alexandre Corrêa. Porto Alegre: EST/SULINA/UCS, 1980. $11 \mathrm{v}$.

TOMBERLIN, J.E. Good Samaritans and Castañeda's System of Deontic Logic. In: TOMBERLIN, J.E. (Ed.). Hector-Neri Castañeda. Dordrecht: D. Reidel Publishing Company, 1986. p. 255-272.

VON WRIGHT, G.H. Deontic Logic. Mind, 60, p. 1-5, 1951.

VON WRIGHT, G.H. A Note on Deontic Logic and Derived Obligations. Mind, 65, p. 507-509, 1956.

VON WRIGHT, G.H. A New System of Deontic Logic. Danish Yearbook of Philosophy, I, p. 173-182, 1964.

VON WRIGHT, G.H. A Correction to a New System of Deontic Logic. Danish Year Book of Philosophy, 2, p. 103-107, 1965.

VON WRIGHT, G.H. On the Logic and Ontology of Norms. In: DAVIS, J.W. et al. (Ed.). Philosophical Logic. Dordrecht: D. Reidel Publishing Company, p. 89-107. 1969.

VON WRIGHT, G.H. A New System of Deontic Logic. In: HILPINEN, R. (Ed.). Deontic Logic: Introductory and Systematic Readings. Dordrecht: D. Reidel Publishing Company, 1971 [1964]. p. 105-120. (Este artigo é uma reimpressão parcial de von Wright 1964, com outros adendos.).

WEINGARTNER, P. Applications of Logic outside Logic and Mathematics: Do Such Applications Force us to Deviate from Classical Logic?. In: STELZNER, W.; STÖCKLER, M. (Ed.). Zwischen traditioneller und moderner Logik: Nichtklassische Ansätze. Padeborn: Mentis, 2001. p. 53-64.

WILliAMS, B. Ethical Consistency. In: WILliAMS, B. Problems of the Self. Cambridge: Cambridge University Press, 1973[1965]. p. 166-186.

ZIEMBA, Z. Deontic Logic. In: MARCISZEWSKI, W. (Ed.). Dictionary of Logic as Applied in the Study of Language: Concepts, Methods, Theories. The Hague: Martinus Nijhoff Publishers, 1981. p. 97-104. 